\title{
Isolation, Screening, FTIR Analysis and GC-MS Studies of Oleaginous Fungi Pleurotus Ostreatus
}

\author{
K.C. Naveena, Ramalingappa B* \\ Department of Microbiology, Davangere University, Davangere-577007, Karnataka, India.
}

*Corresponding Author: Ramalingappa B, Department of Microbiology, Davangere University, Davangere, Karnataka, India.

\begin{abstract}
D-Glucose is one of the abundant pentose sugars in nature. To isolate oleaginous fungi that can utilize glucose. Fungi were isolated from different soil samples by using yeast peptone agar medium, and then screened by qualitative analysis of Sudan Black B staining method, confirmation of lipid by FTIR spectroscopy. Extraction of lipids by Bligh and Dyer method that showed $6.08 \mathrm{~g} / \mathrm{L}$ of dry biomass, $1.452 \mathrm{~g} / \mathrm{L}$ of lipid yield and $24.25 \%$ of lipid productivity. The potential lipid producer was identified as Plurotus ostreatus. The obtained lipids were determined by GC-MS analysis, containing saturated and monounsaturated fatty acids. These microbial lipids can be used for the production of biodiesel.
\end{abstract}

Keywords: Sudan black B staining, FTIR, Plurotus ostreatus, GC-MS.

\section{INTRODUCTION}

As of late microbial lipids are considered as one of the potential option to Biodiesel production. In nature many microorganisms at the point when grown under supplement pressure conditions (High $\mathrm{C}: \mathrm{N}$ ) proportion including bacteria, fungi, yeast and green algae capable of producing microbial oils [1-6]. The production of lipids is major concern for commercialization by utilizing the low cost materials. The number of oleaginous microorganisms presently being used for production of energy is limited, for example, of the 600 yeasts just $25 \%$ are known to produce lipids and among 60,000 fungal species under 50\% are known to accumulate lipids [7]. In spite of the fact that the numbers appear to be large, the quantity of oleaginous microorganisms being used is limited, since the microbial lipid production explore and application as of recently is centered on production of uncommon lipids rich in poly unsaturated fats. In addition, microorganism fermentation had numerous favorable circumstances over oil bearing plants and crops. In any case, most of oil producing microorganism known at this point could just utilize glucose to produce oil $[8,9,10]$. Creating biodiesel along these lines raises worries about the monetary efficiency, which limits the improvement of microorganism fermentation. For example, a filamentous fungus such as Mortierella alliacea strain accumulated arachidonic acid (ARA) in the form of triglyceride, which have significantly produced $46.1 \mathrm{~g} / \mathrm{L}$ of dry biomass, 19.5 $\mathrm{g} / \mathrm{L}$ of total fatty acid and $7.1 \mathrm{~g} / \mathrm{L}$ of arachidonic acid. Hence, it is clear that oleaginous yeast and fungi will act as potential alternative oil resources for biodiesel production [11]. The present work aim to select an oleaginous fungus that is able to accumulate intracellular saponifiable lipids suitable for production of biodiesel when grown with glucose as carbon source.

\section{MATERials AND Methods}

\subsection{Collection of soil samples}

45 soil samples had been collected from different types of garden. Bulk samples were collected 2-3 $\mathrm{cm}$ below the surface and they were stored at $4^{0} \mathrm{C}$.

\subsection{Isolation and Screening of Fungi for Lipid Production}

Isolation of lipid producing microorganisms was done by spread plate technique. For isolation $0.1 \mathrm{ml}$ or 100 micro liter of diluted soil suspensions were spread on yeast peptone dextrose agar plates (YPD),

after incubation pick the single colonies were streaked and maintained as pure cultures for further study. 
The isolated single colonies of fungi were screened by Sudan black B technique for their lipid producing capacities. The strains which demonstrated positive for Sudan black B staining were kept in cryovials and stored under refrigerated conditions [12].

\subsection{FTIR Analysis (Fourier Transform Infrared Spectroscopy)}

Confirmation of lipid functional groups by FTIR spectroscopy using Thermo Scientific Nicolet 6700. The spectrum range analyzed by device was set from 500 to $4000 \mathrm{~cm}-1$.

\subsection{Determination of Fungal Dry Biomass and Extraction of Lipids}

A loop full of culture was transferred to $50 \mathrm{ml}$ of inoculation media in $100 \mathrm{ml}$ of Erlenmeyer flask, kept on a rotary shaker at room temperature at $160 \mathrm{rpm}$ for two days. After two days of incubation 5 $\mathrm{ml}$ of inoculated culture was transferred to $45 \mathrm{ml}$ of nitrogen limited media containing glucose; 40 $\mathrm{g} / \mathrm{L},(\mathrm{NH} 4) 2 \mathrm{SO} 4 ; 2 \mathrm{~g} / \mathrm{L}, \mathrm{KH} 2 \mathrm{PO} 4 ; 7 \mathrm{~g} / \mathrm{L}, \mathrm{MgSO} 4,7 \mathrm{H} 2 \mathrm{O} ; 1.5 \mathrm{~g} / \mathrm{L}$ and yeast extract; $1 \mathrm{~g} / \mathrm{L}$ with the $\mathrm{pH}$ 5.5 , then incubated at $28^{\circ} \mathrm{C}$ at $160 \mathrm{rpm}$ for 5 days. $50 \mathrm{ml}$ of this culture was harvested by centrifugation at $5000 \mathrm{rpm}$ for $10 \mathrm{mins}$, and then biomass was washed twice with distilled water and dried at $60^{\circ} \mathrm{C}$ for constant mass. The biomass was then determined gravimetrically [13, 14].

Extraction of lipids was done by Bligh and Dyer method. The dried biomass is following by added 10 $\mathrm{ml} 4 \mathrm{M} \mathrm{HCl}$ and incubated at $60^{\circ} \mathrm{C}$ for $3 \mathrm{hrs}$. Then the acid hydrolyzed mass was stirred with $20 \mathrm{ml}$ of chloroform: methanol mixture (1:1) at room temperature for $3 \mathrm{hrs}$ followed by centrifugation at 2000 rpm for 5 mins to separate aqueous upper phase and organic lower phase. Followingly, lower phase containing lipids were recovered and dry lipids were weighed [15].

\subsection{Identification of Potential Lipid Producer and Determination of Fatty Acid Composition by GC-MS}

The total DNA of fungal culture was extracted and genomic characterization was done by $18 \mathrm{~S}$ rRNA typing [16, 17]. After extraction of lipids from fungus, fatty acids determination by gas chromatography with mass spectroscopy (GC: Agilent 7890A MS: 5975C MSD) fitted with DB 5 MS column (Dimensions: $30 \mathrm{~m} \mathrm{~L} \mathrm{x} 0.25 \mathrm{~mm}$ ID x $0.25 \mathrm{um}$ film thickness) 2, 6 dihydroxyacetophenone used as standard for indicate the percentages of all components.

\section{RESULTS}

\subsection{Isolation of Oleaginous Fungi}

In this preliminary study, several colonies with typical morphology of fungi were isolated from different types of soil with glucose used as sole carbon source.

\subsection{Screening and Characterization of Potential Lipid Producer}

Then all the isolates were screened for lipid accumulation capacity by Sudan Black B staining and observe under oil immersion microscope for the presence of intracellular lipids. Out of several microbes only potential fungus selected for characterization, and even it produced more than $20 \%$ of their lipid productivity known as oleaginous.

\subsection{Lipid Functional Groups Confirmed by FTIR Technique}

In analytical graph of FTIR, significant peaks were made between 1600-1820 cm-1 that shows the presence of carbonyl groups. There are peaks between 2850 to $2929 \mathrm{~cm}-1$ that indicates the presence of methyl group. These two functional groups confirmed the intracellular lipids present in Plurotus ostreatus.



Figure1 


\subsection{Determination of Lipid Productivity and Extraction of Lipids}

The isolated organism was characterized for further studies such as dry biomass, lipid yield and lipid productivity, which are given in the following table; 1.

Table1. Details of isolate

\begin{tabular}{|c|c|c|c|c|}
\hline Name & Dry biomass (g/L) & Lipid yield g/L & Lipid productivity (\%) & $\begin{array}{c}\text { Organism } \\
\text { identified }\end{array}$ \\
\hline $\begin{array}{c}\text { MBY- } \\
26\end{array}$ & 6.08 & 1.452 & 24.25 & $\begin{array}{c}\text { Plurotus } \\
\text { ostreatus }\end{array}$ \\
\hline
\end{tabular}

\subsection{Statistical Analysis}

All trials (experiments) were performed in triplicates and data were investigated using one way analysis of variance (ANOVA). Differences with $\mathrm{p}<0.05$ were considered statistically significant.

\subsection{Genomic Characterization of Fungus and Fatty Acid Composition by GC-MS Analysis}

The selected oleaginous fungus strain was identified based on 18S rRNA sequencing. The 18S rRNA was amplified by PCR using various primers set and sequenced. The obtained sequences were BLAST search against NCBI data base, and result showed highest similarity sequence to strain Plurotus ostreatus has the accession number MN049516.

Lipid samples produced by fermented was analyzed by Gas chromatography with mass spectroscopy, relative fatty acid content as shown in table; 2 .

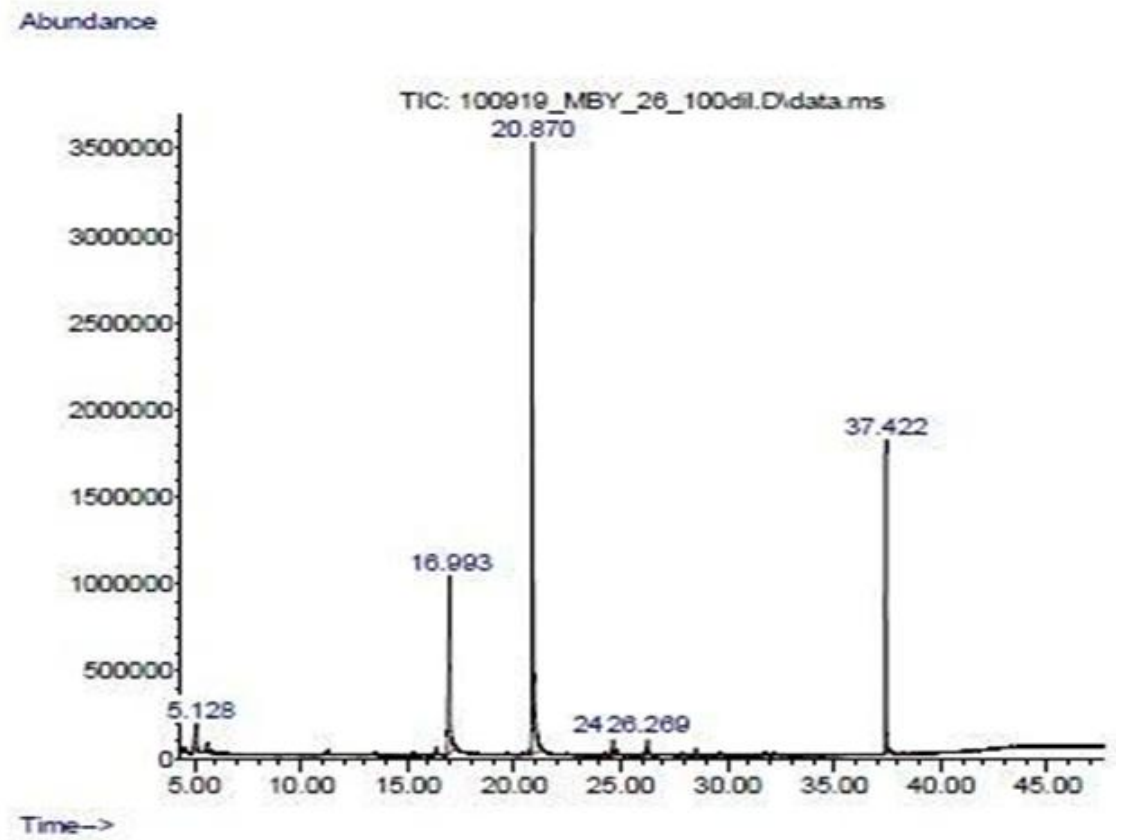

Fig2. Fatty acid profile of fungi by GC-MS analysis

Table2. Details of \% of compounds present in lipids

\begin{tabular}{|c|c|c|c|}
\hline Peak & Retention time & Compound name & \% of compound \\
\hline 1 & 5.128 & Isocrotonoic acid & 3.888 \\
\hline 2 & 16.993 & Ethyl cyclopropanecarboxylate & 21.409 \\
\hline 3 & 20.870 & 2', 6'-Dihydroxyacetophenone & 53.224 \\
\hline 4 & 24.649 & 2-Butenoic acid, 1-methylethyl ester & 0.895 \\
\hline 5 & 26.269 & Methyl 13- methyltetradecanoate & 1.018 \\
\hline 6 & 37.422 & 1.2- Benzenedicarboxylic acid & 19.566 \\
\hline
\end{tabular}

Analysis of lipid sample from fungus showed the occurrence of significant amounts of the saturated fatty acid is: - Methyl 13- methyl tetradeconoate and monounsaturated fatty acid is: - Ethyl cyclopropanecarboxylate, and other compounds such as Isocrotonoic acid, 2',6'Dihydroxyacetophenone, 2-Butenoic acid, 1-methylethyl ester and 1,2-Benzenedicarboxylic acid, mono (2-ethylhexyl) ester were present in total amount of lipids. 


\section{DISCUSSION}

The basic mechanism of lipid accumulation in microorganisms has been well studied $[18,19]$. When lacks the nitrogen source in culture medium, the isocitric dehydroginase (TCDH) stifles, in this manner the tricarboxilic acid course (TCA) was blocked. Additional carbon source was changed to glyceride (TAG) by the series of enzymes like the citric acid lytic enzyme, the malic acid enzyme, the fatty acid enzyme, thus the completed fat accumulation. In this study isolation of oleaginous fungi from soil samples and primary screening was done by qualitative analysis of Sudan Black B staining method, after that confirmation of lipid functional groups by FTIR spectroscopy. The secondary screening done by submerged fermentation, the fungus Plurotus ostreatus showed $6.08 \mathrm{~g} / \mathrm{L}$ of dry biomass, $1.452 \mathrm{~g} / \mathrm{L}$ of lipid yield and $24.25 \%$ of lipid productivity in nitrogen limited media. Other fungi such as Mortierella alpine, M. ramanniana and M. hyaline showed its lipid productivity is $37 \%$, $19 \%$, and $18 \%$ respectively in potato dextrose broth [20].

The degree of lipid accumulation in microorganisms is dictated by their hereditary constitution and the greatest lipid content achievable changes among species and even among singular strains. Oleaginous yeasts furthermore, fungi have been accounted for to be the potential elective oil assets for biodiesel production [21].

\section{CONCLUSION}

The isolated fungus Plurotus ostreatus could grow and accumulate lipid in glucose supplemented with some of inorganic salts. The cell growth and lipid productivity was determined. This study has shown that carbon source glucose is mediated for the accumulation of high amount of intracellular lipids and it can be a promising source for biodiesel production.

\section{REFERENCES}

[1] Ratledge C., Fatty acid biosynthesis in microorganisms being used for Single Cell Oil production, Biochimi. 86 (11), 807-815 (2004).

[2] Shi S., Valle-Rodriguez J.O., Siewers V., Nielsen J., Prospects for microbial biodiesel production, J. of Biotechnol. 6 (3), 277-85 (2011).

[3] Li Q., Du W., Liu D., Perspectives of microbial oils for biodiesel production, Applied Microbiol and Biotech. 80 (5), 749-56 (2008).

[4] Li P., Miao X., Li R., Zhong J., In situ biodiesel production from fast-growing and high oil content Chlorella pyrenoidosa in rice straw hydrolysate, J. Biomed. Biotechnol. 141, 207 (2011).

[5] Meng X., Yang J.M., Xu X., Zhang L., Nie Q.J., Xian M., Biodiesel production from oleaginous microorganisms. Renew. Energy. 34 (1), 1-5 (2009).

[6] Coradini A., Anschau A., Vidotti A., Reis É., Cunha Abreu Xavier M., Coelho R, et al., Microorganism for Bioconversion of Sugar Hydrolysates into Lipids. In: Kamm B, editor. Microorganisms in Biorefineries, Springer Berlin Heidelberg. 51- 58 (2015).

[7] Ratledge C., Wynn J.P., The biochemistry and molecular biology of lipid accumulation in oleaginous microorganisms, Adv. Appl. Microbiol. 51, 1-51 (2002).

[8] Li Y., Zhao Z., Bai F., High-density cultivation of oleaginous yeast Rhodosporidium toruloides Y4 in fed batch culture, Enzyme Microb. Technol. 41 (3), 312-317 (2007).

[9] Loffhagen N., Hartig C., Harms H., Impact of membrane fatty acid composition on the uncoupling sensitivity of the energy conservation of Comamonas testosterone ATCC 17454, Appl. Microbiol. Biotechnol, 70 (5), 618-624 (2006).

[10] Papanikolaou S., Komaitis M., Aggelis G., Single cell oil (SCO) production by Mortierella isabellina grown on high-sugar content media, Bioresour. Technol. 95 (3), 287-291 (2004).

[11] Singh A., Ward O.P., Production of high yields of arachidonic acid in a fed-batch system by Mortierella alpine ATCC 32222, Appl. Microbiol and Biotechnol. 48 (1), 1-5 (1997).

[12] Thakur M.S., Prapulla S.G., Karanth N., Microscopic Observation of Sudan Black B Staining to monitor Lipid production by Microbes, Journal of Chemical Technol and Biotechnol. 42 (2), 129-134 (1988).

[13] Pan L.X., Yang D.F., Shao L., Li W., Chen G.G., Liang Z.Q., Isolation of oleaginous yeast from the soil and studies of their lipid-producing capacities, Food technol and Biotechnol. 47, 215-220 (2009).

[14] Kraisintu P., Yongmanitchai W., Limtong S., Selection and optimization for lipid production of a newly isolated oleaginous yeast, Rdodosporidium toruloides DMKU3-TK16. 44, 436-445 (2010). 
[15] Bligh E.G., Dyer W.J., A rapid method of total lipid extraction and purification, Canadian Journal of Biochem and Physiology. 37, 911-917 (1959).

[16] Edwards U., Rogall T., Blocker H., Emde M., Bottger EC., Isolation and direct complete nucleotide determination of entire genes: characterization of gene coding for 16S ribosomal RNA, Nucleic Acids. 17 (19), 7843-7853 (1989).

[17] Edgar R.C., Muscle: multiple sequence alignment with high accuracy and high throughput. Nucleic Acids Res. 32 (5), 1792-1797 (2004).

[18] Botham P.A., Ratledge C., A biochemical explanation for lipid accumulation in Candida 107 and other oleaginous micro-organisms, J. Gen. Microbiol. 114 (2), 361-375 (1979).

[19] Evans CT., Scragg AH., Ratledge C., Regulation of citrate efflux from mitochondria of oleaginous and non-oleaginous yeasts by adenine nucleotides. Eur. J. Biochem. 132, 609-615 (1981).

[20] Ravikumar K., Dakshayini J., Girisha ST., Biodiesel production from oleaginous fungi, International Journal of Life sciences. 6 (1), ISSN 2091-0525 (2012).

[21] Meng X., Yang J., Xu X., Zhang L., Nie Q., Xian Mo., Biodiesel production from oleaginous microorganisms. Renew. Energ. 34 (1), 1-5 (2009).

Citation: Ramalingappa B, et.al. "Isolation, Screening, FTIR Analysis and GC-MS Studies of Oleaginous Fungi Pleurotus Ostreatus”. International Journal of Research Studies in Biosciences (IJRSB). 7(12), pp. 22-26. DOI: http://dx.doi.org/10.20431/2349-4050.0712003

Copyright: (C) 2019 Authors this is an open-access article distributed under the terms of the Creative Commons Attribution License, which permits unrestricted use, distribution, and reproduction in any medium, provided the original author and source are credited. 